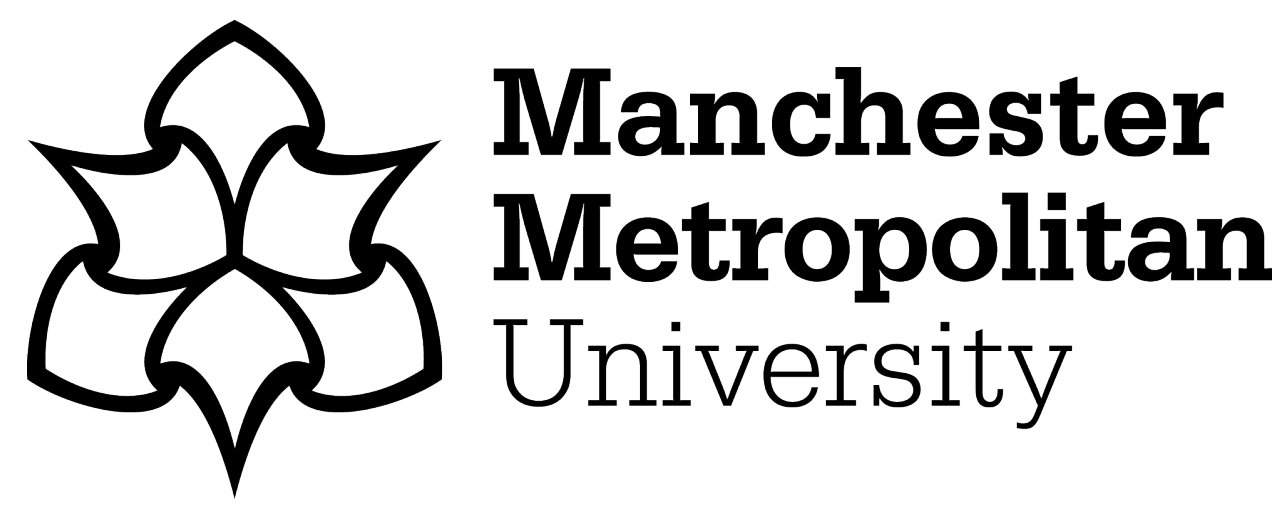

Pearson, SJ and Onambélé, GL (2012) Computation methods affect the reported values of in vivo human tendon stiffness. Journal of The Mechanical Behavior of Biomedical Materials, 5 (1). pp. 291-297. ISSN 1751-6161

Downloaded from: https://e-space.mmu.ac.uk/188590/

Version: Accepted Version

Publisher: Elsevier

DOI: https://doi.org/10.1016/j.jmbbm.2011.08.008

Please cite the published version 


\section{Computation methods affect the reported values of in vivo human tendon stiffness}

Stephen J Pearson $\mathrm{PhD}^{\mathrm{a}}$ and Gladys L Onambélé $\mathrm{PhD}^{\mathrm{b}}$

${ }^{a}$ Centre for Health, Sport and Rehabilitation Sciences Research, University of Salford Manchester M6 6PU. ${ }^{b}$ Institute for Performance Research, Department of Exercise \& Sport Science, Manchester Metropolitan University, Crewe Green Road, Crewe, CW1 5DU.

\section{Corresponding author: Dr Stephen Pearson}

Centre for Health, Sport and Rehabilitation sciences research, University of Salford Manchester M6 6PU.

Tel: +44 (0) 1612952673 Email: $\underline{\text { s.pearson@salford.ac.uk }}$

Word count: 2,601 
Computation methods affect the reported values of in vivo human tendon stiffness 


\begin{abstract}
$\underline{\text { Abstract }}$
Purpose: Scientific validity is questionable when findings from studies cannot be used to make sense of physiological and/or biomechanical data. In particular, is the case of in vivo determination of tendon stiffness (K). Here, approaches range from taking the gradient a) throughout the data range of resting to Maximal Voluntary Contraction (MVC), b) tangents at individual data points, c) linear regressions at discrete force levels (b and c being 'reference standard' as they utilise a number of distinct regions of the force-elongation relationship (FER)).

Study design: A mathematical model approach is used to develop simple curvilinear FERs as seen when determining tendon mechanical properties, to allow variable calculations of $\mathrm{K}$.

Objectives: To compare variability in K estimates using the various approaches currently seen in the literature Methods: Three FER models were developed, representing low, medium and high K. Values of K were determined and compared using the approaches reported in the literature to estimate the magnitude of the difference between attained values of $\mathrm{K}$.

Results: Through mathematical modelling, we demonstrate that the impact on the recorded value of K is substantial: relative to the reference standard methods, published computation methods range from underestimating $\mathrm{K}$ by $26 \%$ to overestimating it by $51 \%$.

Conclusion: This modelling helps by providing a 'scaling factor' through which to minimise the between studies variability associated with computational methods differences. This is especially important where researchers or clinicians require values which are consistent in the context of establishing the 'true' tendon mechanical properties to inform models or materials based on the biological properties of human tendon.
\end{abstract}

Key words: Modelling, Ultrasound, Non invasive, Tendon properties_ 


\section{$1.1 \underline{\text { Introduction }}$}

Characterisation of tendon mechanical properties is important for a number of reasons. For example, it enables a more complete understanding of this tissue's responses to ageing [3,4,9] loading $[6,12,13,14,16,17]$ and gender effects $[2,3,15,21]$. This understanding of human tendon mechanical properties can inform the development for example, of artificial biomaterials suitable in terms of function and optimised from a mechanical perspective, based on living tissue data.

Currently, methods used to calculate in vivo human tendon mechanical properties are somewhat diverse between research groups, a difference which may underlie the variability in the reported values. Hence in order to develop normative reference values for tendon mechanical properties it would be useful to determine a standardised method in order to allow comparisons and 'pooled' data to be available. Indeed, in order to make an informed decision regarding the values of mechanical tendon properties for any given sub population for potential application of a synthetic biomaterial, it would require at least, similar protocols to be adhered to, in order to have some confidence in the property being indeed characteristic of said population.

Methodologies to determine in vivo human tendon mechanical properties using non-invasive techniques have been described [25] through the combined use of dynamometry (to record joint torques), electromyography (to infer and correct for, antagonist(s) co-contraction torque), magnetic resonance imaging (to measure tendon moment arm) and B-mode linear ultrasound imaging (to record tendon/aponeurosis displacement) during ramped skeletal muscle contractions. To date, the principal focus for the research aimed at examining and describing in vivo human tendon mechanical properties have been the superficial tendons (patellar and gastrocnemius) of the lower limb. This in part is due to the less complex arrangement of the tendon - lever arm (which is required for the determination of tendon forces), and partly due to the linear arrangement of these tendons' structures.

Regarding tendon stiffness, the literature shows a large range of values for specific sub-populations. There are undoubtedly a number of potential reasons why differences should be apparent, ranging from inherent variation within/between the sub-populations, to methodological issues including tendon moment arm estimation/differences, whether joint rotation and muscle co-contraction have been accounted for, the total contraction time and which 
portion of the tendon (proximal vs. distal, superficial vs. deep, tendon proper vs. aponeurosis) is imaged. Even where all things are equal (i.e. populations, interventions and methodological parameters are standardised between comparable studies), there is a variety of calculation methods currently employed in the literature to determine tendon stiffness (essentially the gradient of the force - elongation record - see below), which we propose here, poses yet another significant issue to the reported data.

To estimate tendon mechanical parameters, simultaneous measures are made of the forces experienced by the tendon and the associated elongation of the tendon. This relationship is then described by an appropriate function, generally a second degree polynomial function forced through zero, in order to calculate the stiffness of the tendon. Thus, to calculate the stiffness of the tissue, it is then a simple matter of determining the gradient of the tendon force elongation polynomial function. An unreported issue with the technique however, is the fact that when determining the stiffness value different studies utilise a variation in the load levels (i.e. relative force or \%MVC- proportion of the Maximum Voluntary Contraction) to which the stiffness function (usually a local linear regression) is constrained. These \%MVC to which the gradient of the force elongation curve is fitted, range from $90-100 \%$ MVC [8] to the average value at above $50 \%$ of maximal voluntary force $[11,26]$, in addition to several other types of iterations. These differences in regression procedures result in different stiffness values for any given data set since the gradient changes with load level (owing to the curvilinear relationship between tendon elongation and tendon force). Certainly, any of the above methods used will clearly be valid within study longitudinal and/or cohort comparisons. However, the considerable variability in values seen in the literature can arguably also be associated with the between studies inconsistencies in the calculation method.

\subsection{Reported values of stiffness}

The following section relates to aspects of tendon properties examined in similar studies where different methods of calculations are reported. It is emphasised here that although within study aspects remain valid, we would argue here that similarity of methodology would remove the between studies variability that is present due to computational differences and so provide a clearer picture of the absolute values in each context (See table 1 for a cross section of sample studies showing a range of stiffness values and methodologies of calculation). 
Notwithstanding inter-studies population differences, the pre-training values of tendon/aponeurosis stiffness vary by up to $\sim 42 \%$ in young populations in the exercise-training-related literature. For instance gastrocnemius tendon stiffness is reported as $43.9 \pm 2.5$ versus $25.6 \pm 9.0 \mathrm{Nmm}^{-1}$ in two studies [1,13] a difference that may be in part due to the method of calculation. The variability of reported tendon $\mathrm{K}$ could impact on what should be regarded to be average values, leading to confusion regarding normative values.

In order to describe a clearer picture of whether tendon properties change with age it would be useful to reduce any variation in the values induced through different methodologies. With age, some studies have shown that tendon stiffness is unchanged [5,8]. However in contrast, other studies have reported an age-related decrease in the stiffness of the patella tendon, quadriceps femoris tendon and aponeurosis and also in the gastrocnemius medialis tendon and aponeurosis (see below) $[10,18]$. It is nevertheless evident that there is a substantial variability in the reported tendon stiffness values for older individuals with values of i) $550.9 \pm 29.2 \mathrm{~N} . \mathrm{mm}^{-1}$ compared with $1929.0 \pm 109.0 \mathrm{~N} . \mathrm{mm}^{-1}$ in the patellar tendon [3,4] or ii) $23.9 \pm 7.1 \mathrm{~N} \cdot \mathrm{mm}^{-1}$ compared with $31.6 \pm 4.1 \mathrm{~N} \cdot \mathrm{mm}^{-1}$ in the triceps surae tendon $[9,22]$. This variability confounds any evaluation of what 'normative' tendon stiffness for a healthy older person ought to be.

\section{$\rightarrow$ [Insert TABLE 1 near here]}

Any gender related differences in tendon properties may relate to intrinsic differences in tendon structure. However, this is still not completely clear as previous work is not consistent regarding methods to determine stiffness. To gain insight to average values for males and females within an age group again methodological consistency would be useful. There are relatively few studies that have examined tendon characteristic differences between males and females. Previous work indicates that females may have a hormonal milieu which is potentially disadvantageous in comparison to males with regards to tendon collagen synthesis. Magnusson and co-workers [19] stated that collagen synthesis in tendinous tissue at rest and after exercise is lower in females compared to men. We have also recently shown that in response to a comparable training stimulus, females responded to a lesser degree than males [23]. Kubo and co workers [15] identified a gender related difference in the medial gastrocnemius tendon and aponeurosis with females having a $38 \%$ lower value for stiffness compared to men (16.5 \pm 3.4 vs. $\left.25.9 \pm 7.0 \mathrm{Nmm}^{-1}\right)$, compared with values of $49.6 \pm 6.3$ vs. $76.7 \pm 7.5$ elsewhere in the literature [2]. Thus the above variation in tendon stiffness values may have at least part of its origins in the different methods used to calculate $\mathrm{K}$. 
For the above-cited works it is possible that the observed variability arises from a number of aspects related to these studies. It may be for example that the sub-populations chosen between the studies are simply heterogeneous; we simply do not know for example the range of stiffness values to expect from any particular population as we have not accessed the whole population. Many factors could influence the respective samples, e.g. lifestyle, habitual activity levels, endocrine milieu and genetic factors. In addition to these however, the differences in the methodologies utilised to determine the mechanical parameters may also play a part in the range of the results (values of K) reported, such as moment arm estimation or determination, correction for joint rotation, muscle co-contraction and contraction duration. However, as no standardised agreed method exists, when the tendon force - elongation data is plotted and a gradient is calculated to estimate stiffness $\left(\mathrm{K}=\mathrm{Nmm}^{-1}\right)$, different workers have utilised yet another varied approach: that of the level of force across which to estimate tendon K. For example Kubo et al. [14] utilised a linear fit of the tendon force-elongation data from above $50-100 \%$. Whereas Burgess et al. [3] fitted tangents at values from $10-$ $100 \%$ of the observed forces. Hansen and co workers [8] calculated $\mathrm{K}$ from the slope fitted between $90-100 \%$ of the force generated. At the other extreme, a line fitted between resting levels of force and $100 \%$ has been previously used [20]. In the present study, we examine the effects on $\mathrm{K}$ by varying the force levels at which $\mathrm{K}$ is calculated.

Hence the methodological and computation differences will likely make comparisons between studies difficult and potentially inaccurate. In fact large differences are often evident in terms of the reported tendon stiffness values and therefore it would seem reasonable to propose a standardisation of the methodology to determine in vivo tendon properties. Thus the aims of the current paper were to 1) Illustrate the variability of reported methods of calculations of the in vivo tendon stiffness 2) Examine the magnitude of differences in tendon stiffness (K) values, as it relates to the method of calculation through mathematical modelling, With the objective of providing a 'scaling factor' to help comparisons across studies.

\section{Material and Methods}

\section{Creation of a set of model data}

Here a model set of force-elongation data was produced on which to calculate $\mathrm{K}$ using existing methods (see figure 1). Each model illustrated either a compliant, stiff or mid-range stiffness tendon as determined through the equations' 
descriptions (See Figure 1), slopes and/or tissue elongation at identical levels of forces. At the onset, the assumption was that these 'virtual models' represent tendons similar in all other aspects including physiologic (e.g. endocrine milieu, genetics, health/training status) and biomechanics (e.g. tissue dimensions, methods of moment arm estimation, joint rotation during contraction, co-contraction and contraction duration) properties, so that only the computation of the data may impact on the resulting $\mathrm{K}$ value. Thus, this hypothetical tendons with maximal force capacity of $\sim 1530$ $\mathrm{N}$, and maximal elongation of $\sim 3,4$ and $5 \mathrm{~mm}$ where described so that the elongation at every $10 \%$ of MVC was plotted again a force level in a manner to describe a second degree polynomial. The 10 data points in each hypothetical tendon (or model) will hereafter be referred to as the 'observed values'. It is using these 'observed' data that different methods of calculating the stiffness of the tendon was carried out.

\section{$\rightarrow$ [Insert FIGURE 1 near here]}

\section{Mathematical modelling of the impact of the computation method on the reported stiffness value}

To further contextualise the above calculations of $\mathrm{K}$, it must be remembered that the rate of change of tendon elongation with force is not in fact constant (indeed a line of the graph is not straight but a second degree polynomial) and thus the gradient of the curve is continuously changing. Mathematically therefore, the gradient at a given point ( $\mathrm{x}$, y) on the curve is optimally defined as the gradient of the tangent to the point on the curve (i.e. the slope of the straight line which touches the curve at that point only). This is what the method utilising tangents every $10 \% \mathrm{MVC}$ (i.e. method 2) pertains to do. Similarly, in the method that utilises linear regressions every $10 \%$ of MVC (i.e. method 3) the data uses short data intervals where minimal iterations are taken on the existing data. Through this reasoning, the methods that could equally be regarded as 'Reference Standards' were found to be method 2 and method 3 since a) The stiffness values are not statistically different between these two methods ( $P>0.05$, paired $t$-test for equivalent ranges of force), $\mathrm{b}$ ) they yielded sum of squared errors (SSE) $=0$, but also $\mathrm{c})$ they utilised the majority of the data $(\mathrm{n}=$ 9), thus reflecting the continuously altering nature of the rate of change in tendon elongation with force.

\section{$\underline{\text { Data analyses }}$}

From this modelling data set and as detailed in table 2, the determination of $\mathrm{K}$ was carried out using 7 different methods as currently used in the literature. The degree to which the computation methods reliably represent the 
original data set (i.e. the Sum of Residuals (or sum of squared errors - SSE)) was also calculated. In order to estimate the magnitude of difference between methods, averages of the methods typically used were determined from the mathematical modelling approach and differences determined by dividing the mean values of $\mathrm{K}$ determined by the gold standard reference method. Here the two reference standards are set as the tangential method every $10 \%$ MVC and the linear regression at $10 \%$ force interval. These two methods take into account a high number of data points as well as discrete shape differences along the force-elongation curve. The average stiffness of the two methods is used as 'average reference standard' (The Stiffness values are not statistically different between these two methods, $\mathrm{p}>0.05$, paired-t-test). The ratio of the $\mathrm{K}$ values (at each point along the force-elongation curve) in each iteration method, relative to the average of the two 'gold standards' are presented as the 'scaling factor' by which to correct data from one study to another.

\section{Results}

When mathematical iterations do not go through the observed data but force regressions through some of the data (e.g. regression between 50-100\%MVC (see Figure 2)), these introduce a systematic error termed 'residual' (i.e. the difference between the linear regression line (values calculated by the model) and the observed data).

\section{$\rightarrow$ [Insert FIGURE 2 near here]}

The greater the total residuals (or Sum of Squared errors - SSE), the less representative of the observations the iteration is considered (i.e. the worse 'fit' of the model to the data). Our calculations show that on the one hand, methods 2, 3, 6 and 7 all yielded SSE $=0$, whereas an increasing magnitude of SSE existed for the other methods of computing $\mathrm{K}$ so that method $5<\operatorname{method} 4<\operatorname{method} 1$, (see table 2 for specifics on each method).

\section{$\rightarrow$ [Insert TABLE 2 near here]}

Our findings (see table 2) show that in the compliant, mid-range and stiff 'tendons', the material stiffness values obtained using 7 different iterations, exhibited ranges of $\sim 305-619 \mathrm{~N} / \mathrm{mm}, 381-773 \mathrm{~N} / \mathrm{mm}$ and $508-1031 \mathrm{~N} / \mathrm{mm}$, respectively. 


\section{Discussion}

The principal objective of the current work was to determine the impact of the calculation method on the reported value of $\mathrm{K}$ and to develop a scaling factor to align previous work. Our findings are conclusive in that depending on the mathematical iteration, the value of $\mathrm{K}$ is markedly different. Scaling factors for tendon stiffness are therefore proposed as a result of these differences.

Furthermore it also became evident that the intrinsic stiffness of the tendon model does not impact on the range of values obtained; there was a 77\% difference between the lowest and the highest tendon stiffness values from the 7 methods and the level of the difference did not change when comparing between model 1 (stiff tendon), model 2 (mid-range stiffness tendon) or model 3 (compliant tendon). What is more, the models illustrate the 'scaling factor' in terms of obtained stiffness values dependent on the computation methodology and this is shown in figure 3 . Thus we

show that compared to the 'reference standards' (these being the linear (at all 10\% MVC intervals) and the tangential slopes every $10 \% \mathrm{MVC}$ - taken due to the tangent of a point being mathematically accurate to determine the instantaneous gradient at a given level of force), other models range from underestimating stiffness by $26 \%$ to overestimating it by $51 \%$. The 'scaling factors' given in figure 3 then are proposed to be useful in order to compare between studies where different methods of calculating tendon stiffness are used (i.e. when utilising 50-100\% linear method estimate of $\mathrm{K}$ is $\sim 22 \%$ over the gold standard, therefore reduce the values by this amount to allow alignment with tangential method). Notably, these scales can also be utilised for Young's modulus calculations as they are simply the same curve functions as described here but using stress - strain rather than force - elongation.

\section{$\rightarrow$ [Insert FIGURE 3 near here]}

\section{Conclusion}

The current study is the first to highlight a major issue of lack of comparability between studies where various calculation methods are used to obtain an estimate of in vivo tendon stiffness. We show that the linear and tangential methods of calculating tendon stiffness, taken every $10 \%$ of MVC, show no statistically significant difference in terms of average slope values $(\mathrm{P}>0.05)$. However, the methods of drawing a straight linear regression $(0-100 \% \mathrm{MVC}$ 
[20]) underestimates the value relative to the above linear/tangential computations every $10 \% \mathrm{MVC}$ by $26 \%$. At the other end of the spectrum, the single tangent at $100 \%$ MVC overestimates tendon stiffness by a factor of $51 \%$. These discrepancies may explain some of the variability, over and above that linked to the studies' populations, interventions and/or laboratory methods, in the data reported in the literature. Bringing together the findings from the literature would therefore mean adopting one methodology. We propose using the tangential method as it most closely represents the data. For retrospective synthesis of findings in the literature, the scaling factors which we present here can be used in order to allow for more informed study comparisons, clinical decisions and/or further research.

\section{$\underline{\text { Acknowledgements }}$}

The authors would like to thank their respective institutions for their continued support in their research endeavours. 


\section{$\underline{\text { References }}$}

1. Burgess KE, Connick MJ, Graham-Smith P, and Pearson SJ. Plyometric vs. isometric training influences on tendon properties and muscle output. J Strength Cond Res 2007;21: 986-989.

2. Burgess KE, Graham-Smith P, and Pearson SJ. Effect of acute tensile loading on gender-specific tendon structural and mechanical properties. J Orthop Res 2009a; 27: 510-516.

3. Burgess KE, Pearson SJ, Breen L, and Onambele GN. Tendon structural and mechanical properties do not differ between genders in a healthy community-dwelling elderly population. J Orthop Res 2009b; 27:820825 .

4. Carroll CC, Dickinson JM, Haus JM, Lee GA, Hollon CJ, Aagaard P, Magnusson SP, and Trappe TA. Influence of aging on the in vivo properties of human patellar tendon. J Appl Physiol 2008;105:1907-1915.

5. Couppé C, Hansen P, Kongsgaard M, Kovanen V, Suetta C, Aagaard P, Kjaer M, Magnusson SP. Mechanical properties and collagen cross-linking of the patellar tendon in old and young men. J Appl Physiol. 2009 Sep;107(3):880-6.

6. de Boer MD, Maganaris CN, Seynnes OR, Rennie MJ, Narici MV. Time course of muscular, neural and tendinous adaptations to 23 day unilateral lower-limb suspension in young men. J Physiol 2007; Sep15;583(Pt 3):1079-91.

7. Duclay J, Martin A, Duclay A, Cometti G, and Pousson M. Behavior of fascicles and the myotendinous junction of human medial gastrocnemius following eccentric strength training. Muscle Nerve 2009;39:819827.

8. Hansen P, Bojsen-Moller J, Aagaard P, Kjaer M, and Magnusson SP. Mechanical properties of the human patellar tendon, in vivo. Clin Biomech (Bristol, Avon) 2006;21:54-58.

9. Karamanidis K, and Arampatzis A. Mechanical and morphological properties of human quadriceps femoris and triceps surae muscle-tendon unit in relation to aging and running. J Biomech 2006;39:406-417.

10. Karamanidis, K, Arampatzis, A, Mademli, L. Age-related deficit in dynamic stability control after forward falls is affected by muscle strength and tendon stiffness. J Electromyogr and Kinesiol 2008;18:980-989.

11. Kubo K, Kanehisa H, Ito M, and Fukunaga T. Effects of isometric training on the elasticity of human tendon structures in vivo. J Appl Physiol 2001a;91: 26-32.

12. Kubo K, Kanehisa H, and Fukunaga T. Effects of different duration isometric contractions on tendon elasticity in human quadriceps muscles. J Physiol 2001b; 536: 649-655.

13. Kubo K, Kanehisa H, and Fukunaga T. Effects of resistance and stretching training programmes on the viscoelastic properties of human tendon structures in vivo. J Physiol 2002;538:219-226. 
14. Kubo K, Kanehisa H, Miyatani M, Tachi M, and Fukunaga T. Effect of low-load resistance training on the tendon properties in middle-aged and elderly women. Acta Physiol Scand 2003a;178: 25-32.

15. Kubo K, Kanehisa H, and Fukunaga T. Gender differences in the viscoelastic properties of tendon structures. Eur J Appl Physiol 2003b;88: 520-526.

16. Kongsgaard M, Reitelseder S, Pedersen TG, Holm L, Aagaard P, Kjaer M and Magnusson SP. Region specific patellar tendon hypertrophy in humans following resistance training. Acta Physiol 2007;191:111121.

17. Kongsgaard M, Qvortrup K, Larsen J, Aagaard P, Doessing S, Hansen P, Kjaer M, Magnusson SP. Fibril morphology and tendon mechanical properties in patellar tendinopathy: effects of heavy slow resistance training. Am J Sports Med 2010;Apr;38(4):749-56.

18. Mademli L, and Arampatzis A. Mechanical and morphological properties of the triceps surae muscle-tendon unit in old and young adults and their interaction with a submaximal fatiguing contraction. J Electromyogr Kinesiol 2008;18: 89-98.

19. Magnusson SP, Hansen M, Langberg H, Miller B, Haraldsson B, Westh EK, Koskinen S, Aagaard P, and Kjaer M. The adaptability of tendon to loading differs in men and women. Int J Exp Pathol 2007;88:237240.

20. Muraoka T, Muramatsu T, Fukunaga T, and Kanehisa H. Elastic properties of human Achilles tendon are correlated to muscle strength. J Appl Physiol 2005;99: 665-669.

21. Onambele GN, Burgess K, and Pearson SJ. Gender-specific in vivo measurement of the structural and mechanical properties of the human patellar tendon. J Orthop Res 2007;25:1635-1642.

22. Onambélé GL, Narici MV, Rejc E, Maganaris CN. Contribution of calf muscle-tendon properties to singleleg stance ability in the absence of visual feedback in relation to ageing. Gait Posture 2007;Sep;26(3):343-8.

23. Onambele-Pearson GL, Pearson SJ. The magnitude and character of resistance-training-induced increase in tendon stiffness at old age is gender specific. Age (Dordr) 2011 Apr 20. [Epub ahead of print].

24. Pearson SJ, Burgess K, Onambele GN. Creep and the in vivo assessment of human patellar tendon mechanical properties. Clin Biomech (Bristol, Avon) 2007; Jul;22(6):712-7.

25. Reeves ND, Maganaris CN, and Narici MV. Effect of strength training on human patella tendon mechanical properties of older individuals. J Physiol 2003;548: 971-981.

26. Reeves ND, Maganaris CN, Ferretti G, and Narici MV. Influence of 90-day simulated microgravity on human tendon mechanical properties and the effect of resistive countermeasures. J Appl Physiol 2005;98:2278-2286. 


\section{Tables and Figures}

TABLE 1. Sample of reported tendon stiffness values in the literature. $\mathrm{K}$ describes stiffness values prior to any intervention on the study population (i.e. baseline values). The abbreviation $\mathrm{m}$ stands for Males and $\mathrm{f}$ stands for Females. Linear final $10 \%$ is a regression between $90-100 \%$ MVC. The duration of contraction to attain the Force-Elongation relationships is described as either slow (8-12 sec) or fast (3-5secs). Also, specifics of whether total (proximal and distal combined) or proximal only displacements of the tendon are quoted since these nuances in methodology have previously been shown to affect tendon K. ${ }^{7,22}$ Note that the Hansen et al., (2006) paper presents values for repeating tendon stiffness assessments on two different days. Data are reported as Mean \pm S.E or $\pm *$ SD. 


\begin{tabular}{|c|c|c|c|c|c|c|}
\hline Study (i.e. reference) & Age group (years) & Gender & $\begin{array}{l}\text { Subjects } \\
\text { characteristics }\end{array}$ & Tendon & Computation method & $\mathrm{K}(\mathrm{N} / \mathrm{mm})$ \\
\hline Carroll et al., (2008) & $\begin{array}{l}27 \pm 2 ; 65 \pm 1 \mathrm{~m} \\
29 \pm 1 ; 66 \pm 2 \mathrm{f}\end{array}$ & $m \& f$ & $\begin{array}{l}\text { untrained to } \\
\text { recreationally } \\
\text { active ( } n=11 \text { young; } \\
26 \text { old })\end{array}$ & $\begin{array}{l}\text { patellar (total) - } \\
\text { slow }\end{array}$ & linear final $10 \%$ & $\begin{array}{l}2924 \pm 332 \text { young } \mathrm{m} \\
2676 \pm 215 \text { old } \mathrm{m} \\
2106 \pm 64 \text { young } \mathrm{f} \\
1986 \pm 231 \text { old } \mathrm{f}\end{array}$ \\
\hline $\begin{array}{l}\text { Kongsgaard et al., } \\
\text { (2007) }\end{array}$ & 24.61 .0 & $\mathrm{~m}$ & untrained & $\begin{array}{l}\text { patellar (total) - } \\
\text { slow }\end{array}$ & linear final $10 \%$ & $3716 \pm 452$ \\
\hline Hansen et al., (2006) & $30 \pm 7$ & $\mathrm{~m}$ & $\begin{array}{l}\text { recreational athletes } \\
(\mathrm{n}=12)\end{array}$ & $\begin{array}{l}\text { patellar (total)- } \\
\text { slow }\end{array}$ & linear final $10 \%$ & $\begin{array}{l}3725 \pm 293- \\
4195 \pm 369\end{array}$ \\
\hline $\begin{array}{l}\text { Kongsgaard et al., } \\
\text { (2010) }\end{array}$ & $\begin{array}{l}32.9 \pm 3.5 \\
\text { (tendinopathic) } \\
31.5 \pm 3.3 \text { (control) }\end{array}$ & $\mathrm{m}$ & $\begin{array}{l}\text { tendinopathic }(\mathrm{n}=8) \\
\text { control }(\mathrm{n}=9)\end{array}$ & $\begin{array}{l}\text { patellar (total) - } \\
\text { slow }\end{array}$ & linear final $20 \%$ & $\begin{array}{l}3487 \pm 392 \text { control } \\
\text { And } 3185 \pm 187 \\
\text { tendinopathic }\end{array}$ \\
\hline *Reeves et al., (2003) & $\begin{array}{l}73.6 \pm 3.4 \text { control } \\
66.4 \pm 1.7 \text { trained }\end{array}$ & $\mathrm{m} \& \mathrm{f}$ & $\begin{array}{l}\text { untrained }(\mathrm{n}=9) \\
\text { control }(\mathrm{n}=9)\end{array}$ & $\begin{array}{l}\text { patellar } \\
\text { (proximal)-fast }\end{array}$ & linear $>60 \% \mathrm{MVC}$ & $\begin{array}{l}1168 \pm 165 \text { control } \\
\text { and } 1376 \pm 235 \\
\text { trained }\end{array}$ \\
\hline $\begin{array}{l}\text { *de Boer et al., } \\
(2007)\end{array}$ & $\begin{array}{l}22.3 \pm 3.8 \\
\text { Control }(\mathrm{n}=8) \\
\text { Intervention }(\mathrm{n}=9)\end{array}$ & $\mathrm{m}$ & $\mathrm{n} / \mathrm{a}$ & $\begin{array}{l}\text { patellar } \\
\text { (proximal) - fast }\end{array}$ & linear -final $30 \%$ & $\begin{array}{l}1898 \pm 292 \text { control } \\
1605 \pm 512 \\
\text { intervention }\end{array}$ \\
\hline Pearson et al., (2007) & $21 \pm 0.5$ & $\mathrm{~m}$ & $\begin{array}{l}\text { recreationally } \\
\text { active }(\mathrm{n}=9)\end{array}$ & $\begin{array}{l}\text { patellar } \\
\text { (proximal)-slow } \\
\text { and fast }\end{array}$ & $\begin{array}{l}\text { tangent at each } 10 \% \\
\text { of MVC }\end{array}$ & $4648 \pm 434$ \\
\hline $\begin{array}{l}\text { Onambele et al., } \\
(2007)\end{array}$ & $\begin{array}{l}23.1 \pm 1.3 \mathrm{M} \\
21.3 \pm 0.9 \mathrm{~F}\end{array}$ & $\mathrm{~m} \& \mathrm{f}$ & $\begin{array}{l}\text { recreationally } \\
\text { active }(n=10 \mathrm{~m}, 10 \mathrm{f})\end{array}$ & $\begin{array}{l}\text { patellar (total)- } \\
\text { fast }\end{array}$ & $\begin{array}{l}\text { tangent at each } 10 \% \\
\text { of MVC }\end{array}$ & $\begin{array}{l}3759 \pm 421 \mathrm{~m} \\
1716 \pm 183 \mathrm{f}\end{array}$ \\
\hline Duclay et al., (2009) & $\begin{array}{l}23 \pm 3 \text { (trained) } \\
24 \pm 3 \text { (control) }\end{array}$ & $\mathrm{m}$ & $\begin{array}{l}\text { untrained }(\mathrm{n}=18 ; \\
8=\text { control, } 10 \\
\text { intervention) }\end{array}$ & $\begin{array}{l}\text { medial } \\
\text { gastrocnemius- } \\
\text { fast }\end{array}$ & linear $>50 \% \mathrm{MVC}$ & $\begin{array}{l}\sim 200 \pm 25 \text { control } \\
\text { and } \\
250 \pm 25 \text { intervention }\end{array}$ \\
\hline
\end{tabular}




\begin{tabular}{|c|c|c|c|c|c|c|}
\hline *Reeves et al., (2005) & $25-45$ & $\mathrm{~m}$ & $\begin{array}{l}\text { bed rested }(\mathrm{n}=9) \\
\text { trained }(\mathrm{n}=9)\end{array}$ & $\begin{array}{l}\text { medial } \\
\text { gastrocnemius - } \\
\text { fast }\end{array}$ & linear $>60 \% \mathrm{MVC}$ & $\begin{array}{l}124 \pm 67 \\
136 \pm 66\end{array}$ \\
\hline Burgess et al., (2009) & $\begin{array}{l}20 \pm 1 \mathrm{f} \\
22 \pm 1 \mathrm{~m}\end{array}$ & $m \& f$ & $\begin{array}{l}\text { untrained females } \\
(\mathrm{n}=17) \\
\text { males }(\mathrm{n}=18)\end{array}$ & $\begin{array}{l}\text { medial } \\
\text { gastrocnemius(p } \\
\text { roximal) -fast }\end{array}$ & $\begin{array}{l}\text { tangent at } 100 \% \\
\text { MVC }\end{array}$ & $\begin{array}{l}50 \pm 6 \text { and } \\
77 \pm 7\end{array}$ \\
\hline
\end{tabular}


TABLE 2. Determination of tendon stiffness using different methods. The force ranges used to determine tendon stiffness (N/mm) are representative of the practices in the literature. $(0-100 ; 50-100 ; 60-100 ; 90-100$ (or final 10\%) and $100 \% \mathrm{MVC}$ ). The values given for both 'Tangent every $10 \%$ MVC' and 'Linear every 10\% MVC' are the mean K over these ranges (i.e. average K over 10-100\% MVC). SSE is the Sum of Squared Errors (i.e. (Observed Predicted $)^{2}$, where the observed data is that from the force-elongation curve, and the predicted data is that from the linear regression or tangential line). For illustration purposes, the SSE related to model data 2 are described here (the pattern is similar for all 3 models).

\begin{tabular}{|c|c|c|c|c|c|c|c|}
\hline & $\begin{array}{l}\text { Linear 0- } \\
100 \% \text { MVC }\end{array}$ & $\begin{array}{l}\text { Tangent } \\
\text { every } \\
10 \% \mathrm{MVC}\end{array}$ & $\begin{array}{l}\text { Linear every } \\
10 \% \mathrm{MVC}\end{array}$ & $\begin{array}{l}\text { Linear 50- } \\
100 \% \text { MVC }\end{array}$ & $\begin{array}{l}\text { Linear 60- } \\
100 \% \text { MVC }\end{array}$ & $\begin{array}{l}\text { Linear 90- } \\
100 \% \text { MVC }\end{array}$ & $\begin{array}{l}\text { Tangent at } \\
100 \% \mathrm{MVC}\end{array}$ \\
\hline Model Data set 1 & Method 1 & Method 2 & $\begin{array}{r}\text { Method } 3 \\
686\end{array}$ & Method 4 & Method 5 & Method 6 & $\begin{array}{r}\text { Method } 7 \\
103084\end{array}$ \\
\hline Model Data set 2 & 380.6 & 509.37 & 514.6 & 623.9 & 649.4 & 746.9 & 773.14 \\
\hline Model Data set 3 & 304.5 & 407.50 & 411.7 & 499.1 & 519.5 & 597.5 & 618.51 \\
\hline SSE (Model 2) & 205044 & 0 & 0 & 2928 & 1383 & 0 & 0 \\
\hline
\end{tabular}


FIGURE1. Model Data sets on which computation analyses were run. Here the second degree polynomial equation to describe a) Model 1 is, $\left.y=173 x^{2}-50 x ; b\right)$ Model 2 is, $y=97 x^{2}-38 x$; c) Model 3 is, $y=62 x^{2}-30 x$.

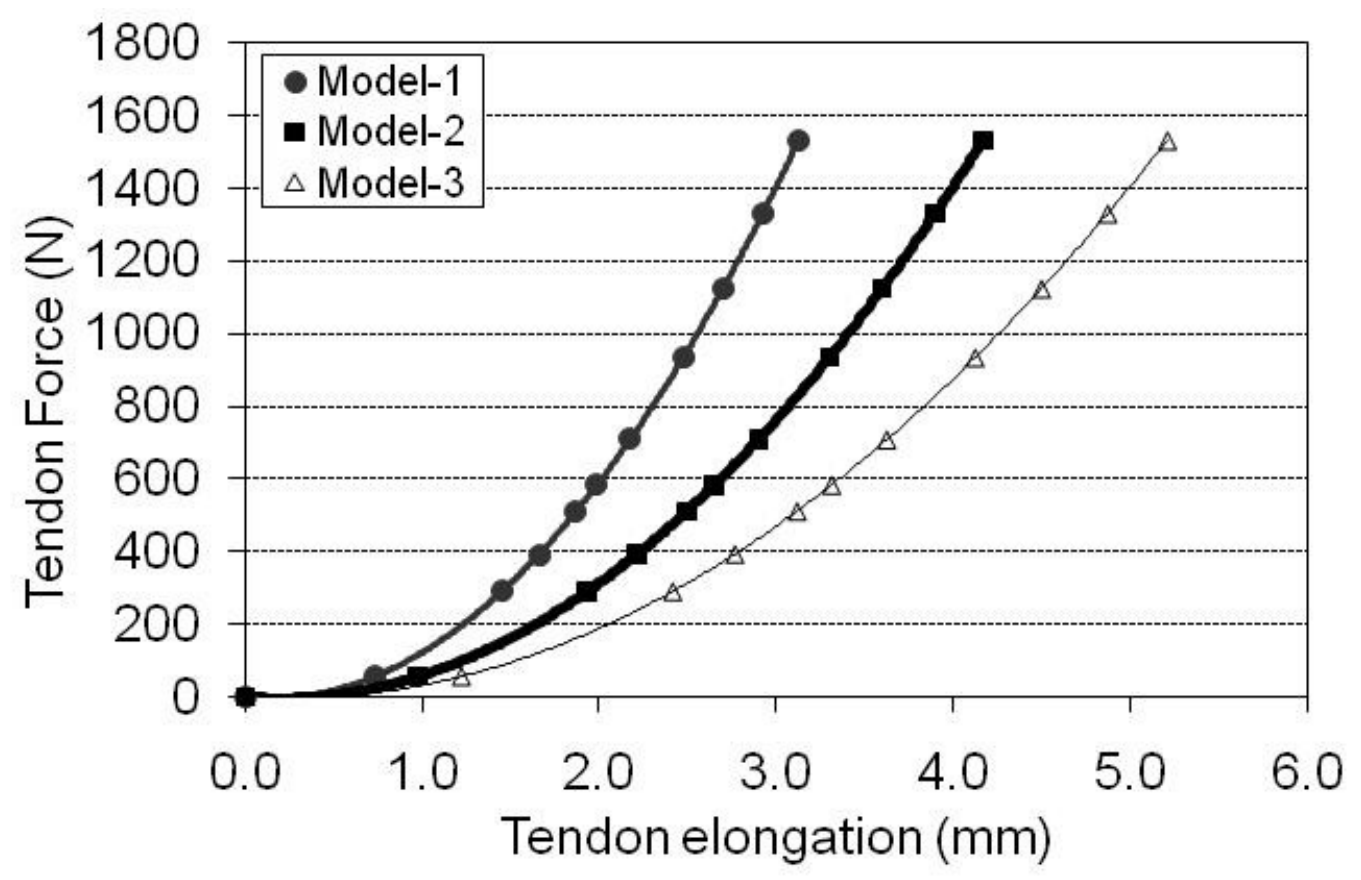


FIGURE 2. Illustration of the most commonly applied methods of computing in vivo tendon stiffness. A) Computation method 1 ( 0 - $100 \%$ MVC linear- grey short dashed line); method 4 (50-100\% MVC linear- grey long dashed line); and method 6 (90-100\% MVC linear- full black line); and B) the two gold standards i.e. Method 3 (linear every 10\%-full grey line) and Method 2 (tangent every 10\%- full black line) are represented against Model Data 2 (square black symbols - i.e. randomly generated data generally in the common shape of the tendon length-tension relationship). The double sided arrow illustrates a residual (i.e. the distance between the Model (or 'observed' value) and computation method 1 at $\sim 240 \mathrm{~N}$ of force.
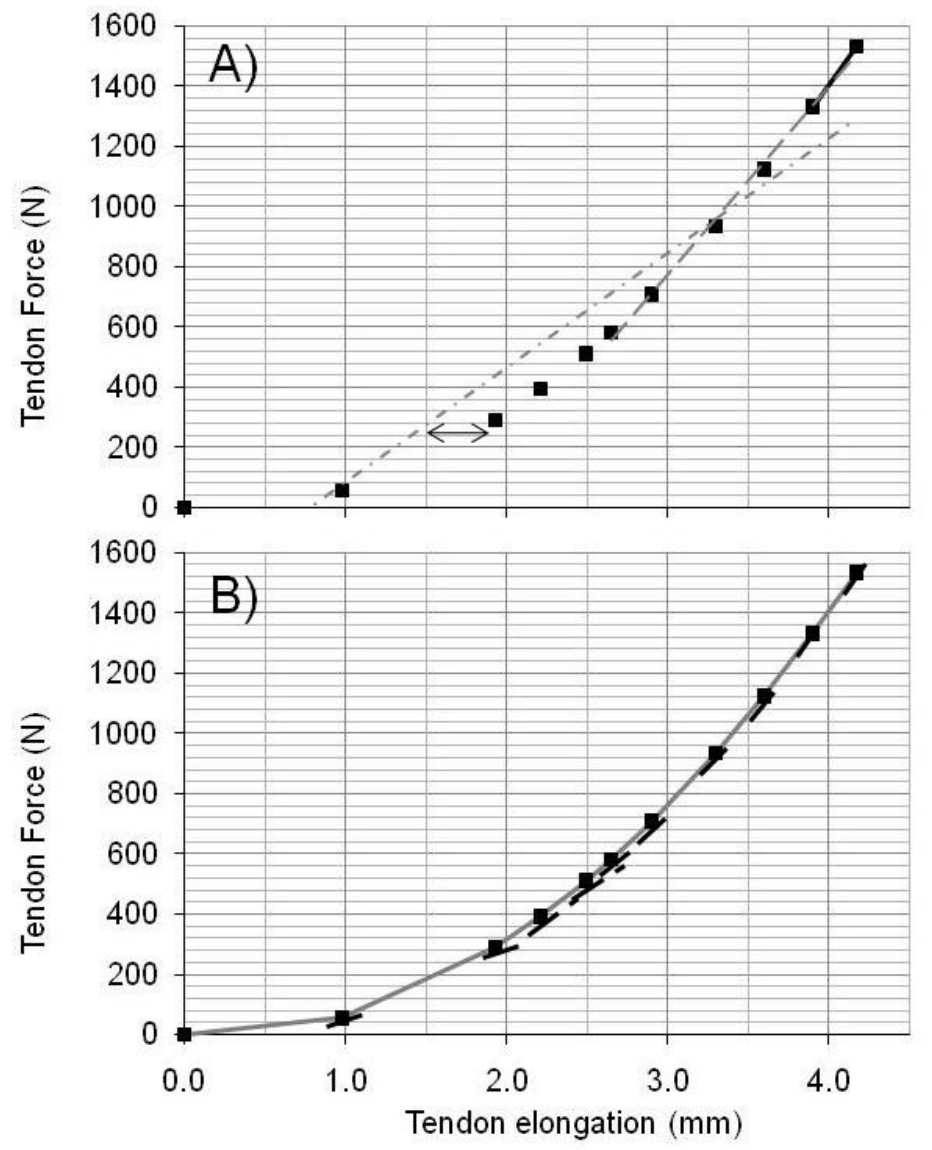
FIGURE 3. Ratio of stiffness (K) values from several methods relative to the two 'reference standard' methods. Here the two reference standards are set as the tangential method every $10 \% \mathrm{MVC}$ and the linear regression at $10 \%$ force interval. These two methods take into account a high number of data points as well as discrete shape differences along the force-elongation curve. The average stiffness of the two methods is used as 'average reference standard' (The Stiffness values are not statistically different between these two methods, $\mathrm{p}>0.05$, paired-t-test). The stiffness values from other comparative methods of calculating $\mathrm{K}$ are divided by this 'average reference standard value'.

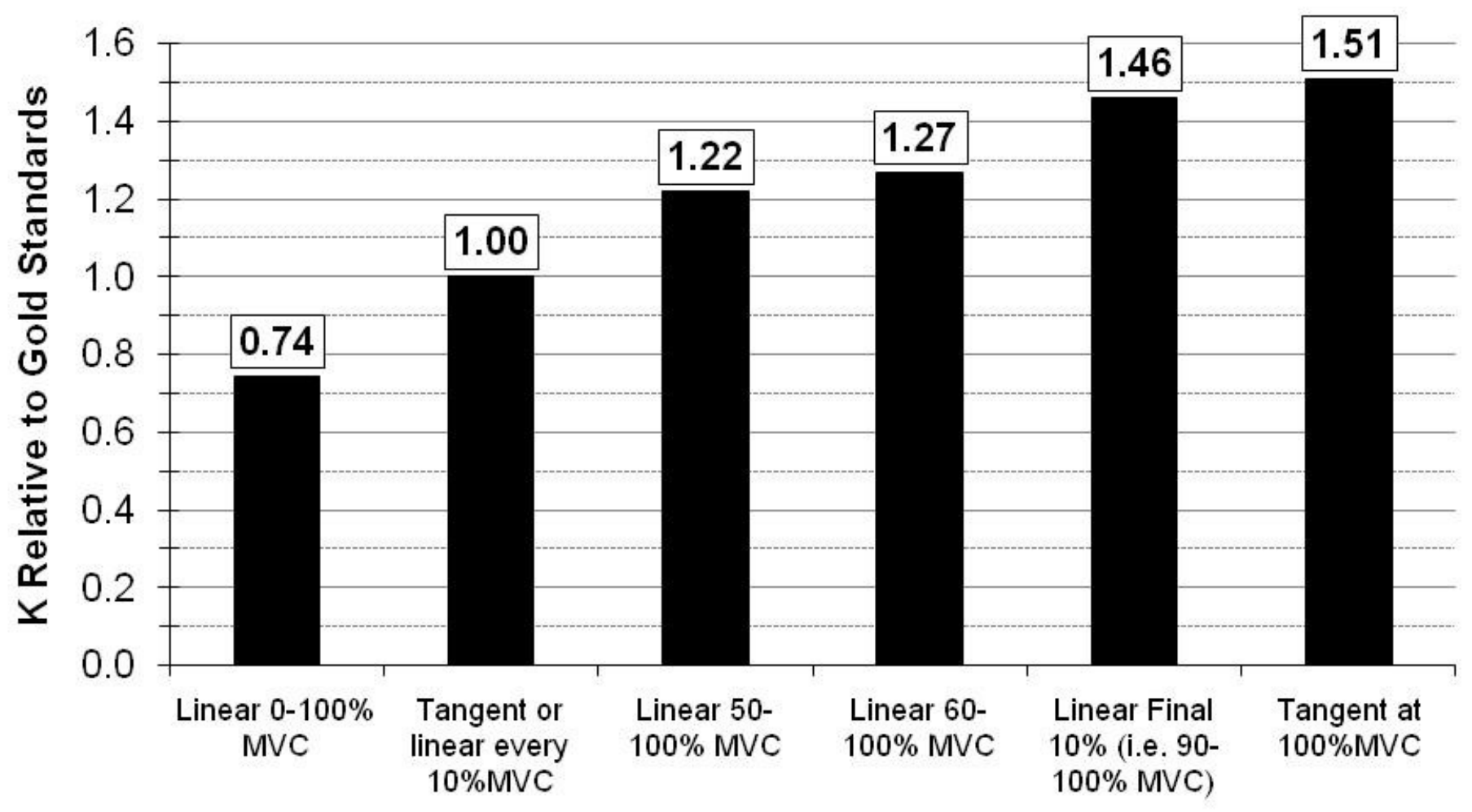

